\title{
Analysis of drugs prescribed in emergency medicine department in a tertiary care teaching hospital in southern Rajasthan
}

\author{
Rakesh Patidar, Meenu Pichholiya*
}

\begin{abstract}
Department of Pharmacology, Geetanjali Medical College and Hospital, Udaipur, Rajasthan, India
\end{abstract}

Received: 25 August 2016

Accepted: 26 September 2016

\author{
*Correspondence to: \\ Dr. Meenu Pichholiya, \\ Email: drmeenupichholiya@ \\ gmail.com
}

\begin{abstract}
Copyright: () the author(s), publisher and licensee Medip Academy. This is an openaccess article distributed under the terms of the Creative Commons Attribution NonCommercial License, which permits unrestricted noncommercial use, distribution, and reproduction in any medium, provided the original work is properly cited.
\end{abstract}

\begin{abstract}
Background: Emergency medicine department of a tertiary care hospital is one of the busiest department and most challenging one for the attending physician. Patients here are in critical condition and treating doctors have to take fast decisions and actions so there are always chances of error in prescribing drugs. Therefore this study was planned with an intention to analyse drug utilization in patients admitted in emergency medicine department using WHO core prescribing indicators.

Methods: A prospective observational study on drugs prescribed in emergency medicine department in a tertiary care hospital was conducted for a period of three months. Data was extracted from 450 patients' case records in a preformed performa after taking approval from institutional ethics committee. Data was analysed by using Microsoft excel. 2010.

Results: 1080 drugs were prescribed in the 450 prescriptions analysed, average being $2.40 \mathrm{drugs}$ per prescription. Analgesics, proton pump inhibitors and antibiotics were the highly prescribed drugs and commonest routes of administration used were intravenous and intramuscular. Approximately 93\% drugs belonged to either or both the WHO and National essential drug lists.

Conclusions: The results of the study disclosed both rational and irrational drug utilization. No polypharmacy was observed but $80 \%$ drugs were prescribed by brand name. Utilization of drugs belonging to essential drug lists indicates judicious use of drugs by our clinicians. Smaller sample size and lack of estimation of cost of treatment are the limitations of this study. Hence more data must be generated for accurate analysis.
\end{abstract}

Keywords: Drug, Emergency medicine, Prescription, Polypharmacy, Routes of administration rationality

\section{INTRODUCTION}

Prescribing drugs is always a challenge for a clinician and especially when it is to be prescribed in emergency. Emergency medicine is the specialty that cares for the care seeker, at the most vulnerable moments of their life. ${ }^{1,2}$ There are always chances of error in prescribing drugs in emergency care department as the patient is in critical condition and physicians has to take quick decisions. Also the clinicians come across various patients with varied unforeseen conditions in acute and unpredictable state. Irrational prescribing of drugs may tend to produce an unproductive and a risky treatment to an individual but a rational drug prescription would see to a least number of drugs used in correct dose and dosage form for appropriate indication and to obtain best possible therapeutic effect of drug in short time. ${ }^{3}$
World Health Organization (WHO) defines drug utilization research as "the marketing, distribution, prescription and use of drugs in a society, with special emphasis on the resulting medical, social, and economic consequences. $^{4,5}$ Drug utilization studies provide insight into pattern of drug utilization and rationality of prescriptions. They help in evidence based guidance for making policy decisions at various levels of health care. This is particularly important in poor and developing countries where there is a need of proper utilization of meagre resources.

Most of the previous studies on drug utilization have been conducted in various departments of medicine but on literature search only few studies of drug utilization in emergency care department were found and no such study has been conducted in our hospital, so we planned a 
drug utilization study in emergency care department of our hospital.

\section{METHODS}

A prospective observational study was conducted in emergency medicine department in a tertiary care hospital over a period of three months. Approval was taken from institutional ethics committee before commencement. All patients irrespective of age, sex and diagnosis were recruited. Data was collected from patients' case records in a preformed performa. Data included demographic profile, patients' complaints, provisional diagnosis, and complete prescription comprising name of drugs, dosage forms, dose and route of administration etc.

Data was analysed by using Microsoft excel 2010 and expressed as percentage. WHO core prescribing indicators were used to analyse the prescriptions. ${ }^{4}$

\section{RESULTS}

Table 1: Frequency of drugs prescribed.

\begin{tabular}{|ll|}
\hline Drugs & $\begin{array}{l}\text { No. of prescription } \\
(\%) \mathbf{N}=\mathbf{4 5 0}\end{array}$ \\
\hline Diclofenac & $150(33.33)$ \\
\hline Ondansetron & $104(23.11)$ \\
\hline Paracetamol & $100(22.22)$ \\
\hline $\begin{array}{l}\text { Antibiotics (Amoxicillin+ } \\
\text { Potassium clavulinate } \\
\text { Ofloxacin + Ornidazole) }\end{array}$ & $84(18.66)$ \\
\hline Budesonide & $67(14.88)$ \\
\hline Tetanus Toxoid & $62(13.77)$ \\
\hline Salbutamol & $60(13.33)$ \\
\hline Rabies Vaccine & $34(7.55)$ \\
\hline Pantaprazole & $30(6.66)$ \\
\hline Isosorbide dinitrate & $30(6.66)$ \\
\hline Aspirin & $30(6.66)$ \\
\hline Clopidogrel & $30(6.66)$ \\
\hline Noradrenalin & $30(6.66)$ \\
\hline Domperidone & $24(5.33)$ \\
\hline Drotaverin & $24(5.33)$ \\
\hline Lorazepam & $24(5.33)$ \\
\hline Fos. Phenytoin & $23(5.11)$ \\
\hline Topical Silver-sulfadiazine & $20(4.44)$ \\
\hline Tramadol & $20(4.44)$ \\
\hline Dopamine & $20(4.44)$ \\
\hline Pheniramine maleate & $20(4.44)$ \\
\hline Dexamethasone & $20(4.44)$ \\
\hline Adrenaline & $10(4.00)$ \\
\hline Atropine & $4(0.88)$ \\
\hline Actrapid Insulin & \\
\hline
\end{tabular}

In the current study total 450 prescriptions were analysed in which total number of drugs prescribed were 1080, the average being 2.40 drugs per prescription.
Table 2: Routes of administration of the drugs prescribed.

\begin{tabular}{|ll|}
\hline Routes of administration & $\begin{array}{l}\text { Numbers of drugs } \\
(\%) \mathbf{N}=1080\end{array}$ \\
\hline Intravenous & $452(41.85)$ \\
\hline Intramuscular & $267(24.72)$ \\
\hline Oral & $216(20)$ \\
\hline Inhalation & $102(9.44)$ \\
\hline Sublingual & $12(1.11)$ \\
\hline Subcutaneous & $10(0.92)$ \\
\hline Topical & $15(1.38)$ \\
\hline Nasal & $6(0.55)$ \\
\hline
\end{tabular}

Among the 450 patients, 270 were males and 180 females and male: female ratio was 1.5:1. Patients of paediatric age group were $9 \% .19 .99 \%$ patients were of the age group less than 40 years, $52.66 \%$ were of the age group between 40 to 60 years and patients of the age more than 60 years were $18.44 \%$.

Table 3: WHO core drug prescribing indicators.

\begin{tabular}{|l|l|l|}
\hline WHO Core prescribing indicators & Results \\
\hline $\begin{array}{l}\text { Average number of drugs per } \\
\text { encounter }\end{array}$ & 2.40 \\
\hline $\begin{array}{l}\text { Percentage of drugs prescribed by } \\
\text { generic name }\end{array}$ & 20 \\
\hline $\begin{array}{l}\text { Percentage of encounters with an } \\
\text { antibiotic prescribed }\end{array}$ & 23.11 \\
\hline $\begin{array}{l}\text { Percentage of encounters with an } \\
\text { injection prescribed }\end{array}$ & \\
\hline $\begin{array}{l}\text { Percentage of drugs prescribed from } \\
\text { essential drug list }\end{array}$ & 92.60 \\
\hline
\end{tabular}

Commonest complain was fever $(18 \%)$ and those due to road traffic accidents $(14 \%)$ followed by gastrointestinal (13\%), cardiovascular ailments $(11 \%)$, complains related to respiratory (10\%) and other organs systems (34\%).

Diclofenac was the maximally prescribed drug, prescribed in $150(33.33 \%)$ prescriptions. Next in order were antimicrobial agents and ondansetron, each being prescribed in $104(23.11 \%)$ patients and paracetamol in $100(22.22 \%)$ prescriptions. Least prescribed drugs were atropine in $10(2.22 \%)$ and insulin in $4(0.88 \%)$ prescriptions. (Table 1)

Most common route of administration of drug was intravenous being $452(41.85 \%)$ in number followed by intramuscular being $267(24.72 \%)$. Least preferred routes were nasal and topical being $6(0.55 \%)$ and $15(1.38 \%)$ in number. (Table 2)

Out of the total 27 drugs used, $66.67 \%$ were included in WHO Model list of Essential Medicine, while 86.89\% drugs were from National list of Essential Medicine, India. $62.96 \%$ belonged to both WHO and National essential drug lists while $7.40 \%$ belonged to none of the 
essential drug lists. $20 \%$ drugs were prescribed by generic name and $19 \%$ were in fixed dose combination form. (Table 3)

Other WHO core prescribing indicators are shown in Table 3.

\section{DISCUSSION}

According to the International Federation for Emergency Medicine it is a field of practice based on the knowledge and skills required for the prevention, diagnosis and management of acute and urgent aspects of illness and injury affecting patients. ${ }^{6}$ Emergency department is one of the busiest but neglected departments as far as drug utilization studies are concerned. Present study was intended to focus on drug use pattern in emergency department.

In our study the average number of drugs prescribed per prescription was 2.40 which is slightly more than the WHO recommended 2.0 drugs per prescription, suggestive of no polypharmacy. ${ }^{7}$ In other studies done by Sait SJ et al., Al Balushi et al. and Barot et al. have reported the average number of drugs prescribed per prescription $2.60,3.2$ and 9.99 respectively. ${ }^{1,3,8}$ Reason for this difference could be due to difference in duration of stay of patient in emergency medicine department. Data in first study was collected for approximately 6 hours and in second study for 48 hours. In our study this value is more close to $\mathrm{WHO}$ recommended value because in our setup patients are referred to respective departments after initial management as soon as possible for the appropriate definitive treatment.

Commonest complains and drugs prescribed in our study also differs from previous studies, probably because of its location our hospital caters to mainly lower socio economic sector of our population in whom infectious diseases are more common.

Maximally prescribed drug was diclofenac which has been delisted from WHO essential drug list because of its cardiac adverse effects. ${ }^{3,9}$ Moreover prescribing it for fever can be judged as irrational prescribing. But prescribing it for pain and inflammation cannot be considered totally irrational as it is still included in National Essential drug list.

Second in order of prescribing drugs were ondansetron and antibiotics. Use of ondansetron in conditions other than vomiting induced by chemotherapy or radiotherapy and post-operative vomiting is it's off label use. ${ }^{10}$ But according to Patawala et al. ondansetron can be used as first line agent for nausea and vomiting in emergency department. $^{1,11}$

In our setup antibiotics were used to a lesser extent as compared to previous studies. Antibiotics should be used as a definitive treatment, if feasible; after performing culture and sensitivity test. The lower incidence of antibiotic use can be due shorter duration of stay of patient in emergency department.

Most frequent route of administration in this study was intravenous followed by intramuscular which is required in emergency settings for the need of faster action, good bioavailability and predictable concentration of drugs. ${ }^{12}$

Approximately $93 \%$ of the prescribed drugs were enlisted in either or both WHO and national essential drug list. ${ }^{13}$ which reflects awareness of physicians for judicious use of drugs.

Number of drugs prescribed by generic name was low (20\%). Generic medicines are more affordable versions of branded medicines sold by companies. In its directive dated $21^{\text {st }}$ January 2013 to the principals of medical colleges, director of hospitals and presidents of all state medical councils, the MCI has said that every physician should, as far as possible, prescribe drugs with generic names. ${ }^{14}$ Nowadays a growing concern is there regarding physician's charm for prescribing newer and expensive drugs as they are lured by pharmaceuticals and sometimes also necessary for patient's satisfaction.

\section{CONCLUSION}

Both rational as well as irrational use of drugs was found in our study as illustrated above; although most of the drug utilization was justified. Polypharmacy was not observed but most of drugs were prescribed by brand names. It is a good practice in our hospital to shift the patients at the earliest to concern departments for better treatment but because of this practice the pattern of drug use and common complains differ from other studies. Smaller sample size as compared to number of patients attending the department is an important limitation of our study. Another important parameter lacking is estimation of cost of treatment. Hence future studies should be planned for accurate analysis.

\section{Funding: No funding sources \\ Conflict of interest: None declared \\ Ethical approval: Not required}

\section{REFERENCES}

1. Barot PA, Malhotra SD, Rana DA, Patel VJ, Patel KP. Drug utilization in emergency medicine department at a tertiary care teaching hospital: A prospective study. J Basic Clin Pharm 2013;4(4):7881.

2. Tintinalli JE, Stapczynski JS, Cline DM, Ma OJ, Cydulka RK, Meckler GD. 7th ed. North Corolina, USA: McGraw-Hill Publishing House; 2011. Tintinalli's Emergency Medicine: A Comprehensive Study Guide.

3. Mohammed Sulaiman SJ, Sarumathy S, Anbu J, Ravichandiran V. Study of drug utilization pattern in 
a tertiary care hospital during the inpatient admittance in the emergency care department. Asian J of Pharm and Clin Res. 2014;7(1):146-8.

4. World Health Organization. Introduction to drug utilization research. Geneva: World Health Organization; 2003.

5. Kaur S, Rajagopalan S, Kaur N, Shafiq N, Bhalla A, Pandhi P, Malhotra S. Drug utilization study in medical emergency unit of a tertiary care hospital in North India. Emerg Med Int. 2014:973578.

6. McCaig LF, Burt CW. National hospital ambulatory medical care survey: 2002 emergency department summary. Adv Data. 2004;340:1-34.

7. Quick JD, Hogerzeil HV, Velasquez G, Rago L. Twenty-five years of essential medicines. Bull WHO. 2002;80:913-4.

8. Al Balushi KA, Al-Shibli S, Al-Zakwani I. Drug utilization patterns in the emergency department: a retrospective study. Journal of Basic and Clinical Pharmacy. 2014;5(1):1-6.

9. McGettigan P, Henry D. Use of non-steroidal antiinflammatory drugs that elevate cardiovascular risk:
An examination of sales and essential medicines lists in low-, middle-, and high-income countries. PLoS Med. 2013;10(2):e1001388.

10. Longo DL, Fauci AS, Kasper DL, Hauser SL, Jameson JL, Loscalzo J. Harrison's Principles of Internal Medicine.18th ed. USA: McGraw-Hill Companies. 2012;2:247.

11. Patanwala AE, Amini R, Hays DP, Rosen P. Antiemetic therapy for nausea and vomiting in the emergency department. J Emerg Med. 2010;39:3306.

12. Srivastav SK. Pharmacology for MBBS.1st ed. New Delhi India: Avichal Publishing Co. 2016. pp 13.

13. Tripathy KD. Essentials of Medical Pharmacology. 7thed. New Delhi India: Jaypee Brothers. 2013;2:957-61.

14. Mukherjee R. Prescribe generic drugs: MCI to doctors. The Times of India [Internet]. (2013, January 27). Available from: articles.timesofindia.indiatimes.com/2013-0127/india/36576717_1_generic-drugs-genericmedicines-generic-versions.

Cite this article as: Patidar R, Pichholiya M.

Analysis of drugs prescribed in emergency medicine department in a tertiary care teaching hospital in southern Rajasthan. Int J Basic Clin Pharmacol 2016;5:2496-9. 